\title{
Measuring the difference between actual and reported food intakes in the context of energy balance under laboratory conditions
}

\author{
R. James Stubbs ${ }^{1,2 *}$, Leona M. O'Reilly ${ }^{1}$, Stephen Whybrow $^{3}$, Zoë Fuller ${ }^{1}$, Alexandra M. Johnstone ${ }^{1}$, \\ M. Barbara E. Livingstone ${ }^{4}$, Patrick Ritz ${ }^{5}$ and Graham W. Horgan ${ }^{6}$ \\ ${ }^{1}$ Rowett Institute of Nutrition and Health, Greenburn Road, Bucksburn, Aberdeen AB21 9SB, UK \\ ${ }^{2}$ University of Derby, Kedleston Road, Derby DE22 1GB, UK \\ ${ }^{3}$ Public Health Nutrition Research Group, Rowett Institute of Nutrition and Health, University of Aberdeen, \\ Aberdeen AB25 2ZD, UK \\ ${ }^{4}$ University of Ulster at Coleraine, Cromore Road, Coleraine, County Londonderry, Northern Ireland, UK \\ ${ }^{5}$ UMR Inserm 1027, Université Paul Sabatier, CHU de Toulouse, France \\ ${ }^{6}$ Biomathematics and Statistics Scotland, The Rowett Research Institute, Greenburn Road, \\ Bucksburn, Aberdeen AB21 9SB, UK
}

(Submitted 8 May 2013 - Final revision received 6 December 2013 - Accepted 2 January 2014 - First published online 17 March 2014)

\begin{abstract}
To date, no study has directly and simultaneously measured the discrepancy between what people actually eat and what they report eating under observation in the context of energy balance (EB). The present study aimed to objectively measure the 'extent' and 'nature' of misreporting of dietary intakes under conditions in which EB and feeding behaviour were continuously monitored. For this purpose, a total of fifty-nine adults were recruited for $12 \mathrm{~d}$, involving two $3 \mathrm{~d}$ overt phases and two $3 \mathrm{~d}$ covert phases of food intake measurement in a randomised cross-over design. Subjects had ad libitum access to a variety of familiar foods. Food intake was covertly measured using a feeding behaviour suite to establish actual energy and nutrient intakes. During the overt phases, subjects were instructed to self-report food intake using widely accepted methods. Misreporting comprised two separate and synchronous phenomena. Subjects decreased energy intake (EI) when asked to record their food intake (observation effect). The effect was significant in women $(-8 \%, P<0 \cdot 001)$ but not in men $(-3 \%, P<0 \cdot 277)$. The reported EI was 5 to $21 \%$ lower (reporting effect) than the actual intake, depending on the reporting method used. Semi-quantitative techniques gave larger discrepancies. These discrepancies were identical in men and women and non-macronutrient specific. The 'observation' and 'reporting' effects combined to constitute total misreporting, which ranged from 10 to $25 \%$, depending on the intake measurement assessed. When studied in a laboratory environment and EB was closely monitored, subjects under-reported their food intake and decreased the actual intake when they were aware that their intake was being monitored.
\end{abstract}

Key words: Misreporting: Under-reporting: Under-eating: Dietary intakes

Energy intake (EI) and diet composition are related to a range of preventable diseases such as obesity, heart disease, diabetes, disorders of lipid metabolism and some cancers. National dietary and public health policies are heavily influenced by large-scale surveys of dietary intakes in relation to a panoply of health outcomes ${ }^{(1-4)}$. Given the scale of interest and resources invested in elucidating the relationship between diet and disease, it is remarkable that so little attention has been given to the fact that, with the exception of the direct observation in laboratory and clinical settings, all dietary intake measurements are self-reported and prone to distortion by the subject. This does not imply that researchers are unaware of the problem of misreporting of dietary intakes ${ }^{(5-8)}$. They simply do not have sufficiently accurate tools at their disposal to account for this problem, and large-scale dietary surveys are obliged to resort to approximate measures that necessitate assumptions about the energy balance (EB) of subjects studied ${ }^{(9,10)}$.

It became apparent over 20 years ago that a large proportion of dietary intake assessments do not represent a plausible level of habitual intake high enough to maintain EB. The development of isotopic techniques to objectively

Abbreviations: DH, diet history; DLW, doubly labelled water; EB, energy balance; EE, energy expenditure; HNU, Human Nutrition Unit; LWI, laboratoryweighed intakes; WDR, weighed dietary record.

*Corresponding author: R. J. Stubbs, fax +44844892 0401, email james.stubbs@slimming-world.com 
measure total energy expenditure (EE) revealed that reporting of EI in study groups usually falls short of actual EE, implying that subjects were either in a negative EB or were misreporting their $\mathrm{EI}^{(11-15)}$. Based on the fundamental principles of $\mathrm{EB}$, it is now generally accepted that under-reporting or misreporting is widespread ${ }^{(6,14,16)}$. In other words, a large proportion of subjects in diet surveys misreport their energy (and probably nutrient) intakes to an extent that would probably distort the relationships between diet and health that inform policy decisions ${ }^{(9)}$.

Despite these considerations, little work has been done to examine the extent to which dietary intake assessments relate to actual food intake. The discrepancy between what people eat and what they say they eat has rarely been directly measured $^{(7,17)}$. Instead, a number of attempts have been made to 'correct' for misreporting statistically by excluding subjects with implausibly low EI from analyses. Initial attempts were made to establish EI:BMR ratios at which intakes can be deemed implausibly low. These cut-offs have been called the Goldberg cut-offs ${ }^{(18)}$. Their use has been inconsistent but widespread in attempting to identify and exclude misreporters from analysis of diet surveys. However, the Goldberg cut-offs only identify implausibly low $\mathrm{EI}^{(6,19)}$. This practice itself requires a number of assumptions, which render the whole process approximate when assessing the degree of misreporting. For example, linear regression equations to predict BMR are approximate and physical activity levels are usually assumed. Moreover, the inclusion or exclusion of misreporters of food intake may distort relationships under investigation ${ }^{(5)}$, because higher reported intakes are also affected by misreporting and are more likely in those with higher activity levels.

Validation of food intake records most commonly compares one self-reported method of collecting dietary intake data with other self-reported methods ${ }^{(20-22)}$. Clearly, if dietary misreporting is a property of the subject itself, those errors between techniques may co-vary, giving false validity of a new technique. A valid report should be free of altered feeding behaviour, such as change in dietary patterns (be it actual behaviour or the subject's report of that behaviour) or false memory. For a report of food intake to be valid, it must reflect what an individual eats and drinks over the measurement period ${ }^{(6)}$.

Attempts have also been made to validate dietary intakes using water ${ }^{(23-25)}$ or $\mathrm{N}$ balance ${ }^{(26-28)}$. These approaches assume that water and $\mathrm{N}$ are fixed proportions of the diet, which of course they are not. At present, there is no reliable biomarker of energy or macronutrient intake that will quantify the nature and extent of misreporting ${ }^{(6)}$. Its true nature and extent are largely unknown.

The overall aim of the present study was to directly measure the nature and extent of misreporting of dietary intakes under carefully controlled laboratory conditions.

The objectives of the present study were to use measures of EB to (1) develop and validate a 'gold standard' measurement of food intake against which self-reported methods can be compared, (2) compare in fifty-nine UK adults, food intake using different self-reported measures with the 'gold standard', under ad libitum feeding conditions in a laboratory environment specifically designed to monitor the accuracy of reporting of dietary intakes, and (3) examine the effect of self-recording intake on actual feeding behaviour in men and women.

\section{Methods and materials}

\section{Study design}

Subjects. A total of thirty normal weight and twenty-nine overweight men and women were recruited from the Aberdeen area. The men and women were stratified into three age categories (20-35, 36-50 and 51-65 years) and two BMI categories $\left(20-25\right.$ and $\left.>25 \mathrm{~kg} / \mathrm{m}^{2}\right)$. Table 1 gives details on the age, height, weight, BMI, RMR and percentage of body fat of the subjects who were included in the study. The purpose of the study was, necessarily, not explained to the subjects. They were informed that the study examined the relationships between diet and lifestyle. All subjects were apparently healthy, and smokers were excluded.

Concept and design of the study. The aim was to develop a 'gold standard' measurement of food intake against which common self-reported dietary intake methods could be evaluated. The 'gold standard' was obtained by covertly monitoring the food intake of subjects who were given access to their own individual kitchen and store of food. Food intake was covertly measured as food disappearance from the individual kitchens. The 'gold standard', here termed 'laboratoryweighed intakes' (LWI), was then validated by comparison with independent measures of the components of EB; EE was measured using doubly labelled water (DLW) and body weight was recorded daily. Thus, EI - EE was compared with EB estimated from changes in weight. Once validated, the 'gold standard' measure of food intake (LWI) was then compared with four common methods for self-assessing food intake in diet surveys.

Protocol. Fig. 1 describes the experimental protocol. On days 1 and 2, subjects were fed a fixed diet designed to maintain EB estimated at 1.6 and 1.5 times RMR, for men and women, respectively. The diet comprised, as a percentage of energy, $35 \%$ fat, $55 \%$ carbohydrate and $15 \%$ protein.

Subjects were studied in a randomised cross-over design for $12 \mathrm{~d}$. During days 3 to 14 , food intake of the subjects was quantified covertly by trained staff (see below). A $7 \mathrm{~d}$ diet history (DH), completed before the study, and shopping list records were used to formulate a list of foods and beverages usually consumed by each subject. Each subject had ad libitum access to these foods and beverages throughout days 3 to 14 . Subjects were asked whether the variety of the food was to their liking, and whether the investigator had omitted any food items usually consumed. If food items had been omitted, these were then purchased and included in the subjects' selection of habitual food intake.

During days 3 to 14 , subjects were studied under the specifically developed environment of the Feeding Behaviour Suite at the Human Nutrition Unit (HNU) at the Rowett Institute of Nutrition and Health. The HNU had a residential suite, which was specifically tailored for unobtrusive, precise, 
accurate measures of energy and nutrient intakes in volunteers. This environment simulated a natural environment, but enabled the nature and extent of misreporting of dietary intakes to be quantified. Normally, food was cooked and provided to volunteers in the metabolic kitchens. This suite was extended for the present study by adding a specifically designed facility that enabled the amount of ingredients used in food preparation and subsequent ingestion to be quantified covertly by staff members. This was achieved by a system in which subjects could not throw leftovers away. All used dishes and cooking utensils were placed in a section of their own kitchen to be removed and surreptitiously quantified by staff. Each subject only had key access to his/her own kitchen. This approach was important since recording errors can arise from errors in the estimate of ingredients used in both preparation and ingestion. Video cameras continually monitored feeding behaviour and compliance to the protocol. Combination of these data allowed the size, frequency, composition of meals and cooking methods to be monitored. Thus, throughout days 3 to 14 , in the HNU, each subject's feeding behaviour was continuously but unobtrusively monitored in the following ways. (1) Each subject could only access food from their own specific kitchen, which contained a fridge, freezer and a cupboard for storage of fresh and dried produce containing food to which only they were allowed ad libitum access. The kitchen contained a small discrete camera and video data were used to cross check, item by item, the validity of the food intakes, calculated from the weight of foods eaten, as determined by the investigators. This qualitative information provided reassurance that the subjects complied with the protocol, i.e. they ate the foods provided. (2) All parts of the HNU were monitored by video camera with the exception of the subjects' private rooms and bathroom facilities. Subjects were not allowed to take food into these areas. Subjects were informed that cameras were present for security purposes, although they were not made overtly aware of the camera in their larders, which resembled an infrared motion detector commonly used in burglar alarm systems. (3) The purpose of the study was to monitor the actual food intake of subjects. Because the subjects were continually resident in the $\mathrm{HNU}$, considerable effort was made to create a comfortable environment. There was continuous staff cover from 07.00 to 21.00 hours throughout the study and a member of staff was on call outside of these hours. If a subject left the laboratory grounds at anytime during the twelve measurement days, they were accompanied

Daily energy intake estimated covertly from the $24 \mathrm{~h} \mathrm{LWI}$ Subjects' self-recorded food intake during the overt phase Ad libitum intake of the normal diet

\begin{tabular}{|c|c|c|c|c|}
\hline MTD & Covert/overt & Overt/covert & Covert/overt & Overt/covert \\
Days 1-2 & Days 3-5 & Days 6-8 & Days 9-11 & Days 12-14 \\
& Assessment of energy expenditure using doubly labelled water \\
\multicolumn{4}{c}{ Daily measurement of body weight }
\end{tabular}

Fig. 1. Experimental protocol. LWI, laboratory-weighed intakes; MTD, maintenance days. 
and observed by a member of staff. It was not possible for anyone to enter or leave the HNU without being monitored by the Institute's security system.

The $12 \mathrm{~d}$ used to quantify the nature and extent of misreporting of food intakes were broken down into four groups of $3 \mathrm{~d}$, the order of which was counterbalanced across the subjects. There were two $3 \mathrm{~d}$ overt phases and two $3 \mathrm{~d}$ covert phases. During the overt phases, subjects were asked to quantify their food intake using a number of self-reporting methods (see below). Furthermore, during the covert phases, subjects were asked to not to quantify their food intake. During this time frame, food intake was covertly quantified on a daily basis by an investigator using the LWI method.

\section{Description of the laboratory-weighed intake method}

All food items were weighed, by research staff, to the nearest $0 \cdot 1 \mathrm{~g}$ on digital scales (Soehnle model 820; Soehnle-Waagen GmbH or Ravencourt model 333; Ravencourt) including the weight of packaging before they were placed into each subject's personal kitchen on day 3. Each subject received bottled water for drinking and their own individual kettle in order to estimate water consumption.

Each subject was given full verbal and written instructions regarding the kitchens including information on waste and packaging and use of kettles and water. Each subject was instructed not to throw any waste away including packaging of food items and peelings and leftovers from meals. Every kitchen contained a special bin for all waste and packaging, with all waste items individually wrapped. Subjects were also instructed not to do any washing of dishes.

Each morning an investigator entered the kitchen before the subject awoke, typically before 06.00 hours, and re-weighed all food items contained in the kitchen using digital scales. These LWI included weights of any leftovers including peelings, packaging found in the subjects' individual bins. This enabled accurate estimates of $24 \mathrm{~h}$ food intake to be calculated. This information was then transcribed onto a $24 \mathrm{~h}$ summary sheet along with a full description of each food item. Subjects were unaware of this procedure, and this constituted the 'gold standard' against which to compare self-reported food intakes.

Each $24 \mathrm{~h}$ summary sheet was doubled checked for errors by cross-checking weights of individual food items, and then entered into Diet 5 (Robert Gordon University, Aberdeen), a computerised version of McCance and Widdowson's composition of foods and supplements ${ }^{(29)}$.

\section{Validation of the laboratory-weighed intakes}

Components of energy balance. The validation of EI against estimated $\mathrm{EE}$ rests on the fundamental physiological equation:

$$
\mathrm{EI}=\text { total } \mathrm{EE} \pm \Delta \text { body stores. }
$$

By comparing EI minus EE with the change in weight for the group of subjects, it was possible to compare two independent measures of EB. Good agreement between the two estimates of EB indicates that actual EI, as measured by LWI, was accurately measured, provided EE and energy stores (i.e. change in body weight) were measured with reasonable precision and accurately.

Measurement of energy expenditure using doubly labelled water. On the morning of day 3, subjects received a bolus dose of DLW to estimate total EE during the $12 \mathrm{~d}$ period (see Fig. 1). At 07.00 hours, subjects were woken and asked to empty their bladders and were weighed. At 09.00 hours, they gave a sample of urine to be used as baseline, along with two further background samples collected on the maintenance days to provide information on the pre-dose isotopic enrichment of the subjects' body water pools. Immediately after providing the 09.00-hour sample, each subject was asked to consume a pre-prepared dose of ${ }^{2} \mathrm{H}_{2}{ }^{18} \mathrm{O}$. The dose, bottle and straw used for dose consumption were weighed before and after dosing to two decimal places to allow for accurate determination of the quantity consumed by the subject. Subjects also consumed $100 \mathrm{ml}$ tap water after the dose to prevent the dose being lost from the subjects' buccal cavity. The dose levels were $0.15 \mathrm{~g} / \mathrm{kg}$ body weight of a $99 \%$ ${ }^{2} \mathrm{H}_{2} \mathrm{O}-\mathrm{H}_{2} \mathrm{O}$ mixture and $1.5 \mathrm{~g} / \mathrm{kg}$ body weight of a $10.0 \%$ $\mathrm{H}_{2}^{18} \mathrm{O}-\mathrm{H}_{2} \mathrm{O}$ mixture for subjects one to forty-two and fortyfour. Dose levels of oxygen 18 were reduced to $0.9 \mathrm{~kg}$ body weight for the last nineteen subjects (i.e. forty-three and forty-five to fifty-nine) because of the world shortage in DLW at the time of the experiment. The dose was made up as a single dose that was sealed and autoclaved the day before dosing. Subjects then collected urine samples at 4, 5 and $6 \mathrm{~h}$ after dosing to enable the plateau to be individually measured $^{(30)}$. For days 4 to 14 inclusive, subjects continued to collect urine samples, at 11.00 hours, which were frozen at $-20^{\circ} \mathrm{C}$ until analysis.

Calculation of average daily energy expenditure over the $12 d$ period. Urine samples were collected for a multi-point stable-isotope analysis using gas isotope ratio MS. The logtransformed data of enrichment by time were extrapolated back to time 0 , giving a theoretical enrichment at time 0 , which provided information on the individual's size of the body water pool assuming the dilution principle.

Isotopic enrichment of the post-dose urine samples was analysed relative to the original background amounts. Pool sizes and flux rates were calculated as described by Coward ${ }^{(31)}$. EE was calculated from $\mathrm{CO}_{2}$ production using the Weir equation ${ }^{(32)}$ :

$$
\mathrm{EE}=4 \cdot 63 \mathrm{CO}_{2}+16 \cdot 49\left(\mathrm{CO}_{2} / \mathrm{RQ}\right),
$$

where RQ is the respiratory quotient. Food quotient was substituted for RQ as it was assumed to be equivalent ${ }^{(32)}$. For each individual subject, food quotient was calculated from macronutrient intakes taken from the LWI, after having adjusted for changes in fat stores resulting from energy imbalance (bodyweight gain or loss) over the DLW measurement period, and assuming an energy value of $29 \mathrm{MJ} / \mathrm{kg}$ and that all changes in body stores were in the form of fat ${ }^{(32)}$

The use of the DLW technique enabled an accurate determination of average daily total EE for the duration of the study.

$R M R$. Respiratory exchange was measured using a ventilated hood system (Deltatrac II, MBM-200; Datex Instrumentarium 
Corporation) under standardised conditions in subjects who were fasted for $12 \mathrm{~h}$ from the previous night. RMR was calculated using the equations of Elia \& Livesey ${ }^{(33)}$.

\section{Energy storage}

Body composition measures. Weight was measured on a digital platform scale (DIGI DS-410; CMS Weighing Equipment) to the nearest $0.01 \mathrm{~kg}$ on a daily basis after voiding and before eating. Subjects were weighed in dressing gowns of a known weight, and body weight was then corrected back to nude.

Height was measured to the nearest $0.5 \mathrm{~cm}$ on day 3 using a portable stadiometer (Holtain Limited). The percentage of body fat was estimated on day 3 using the skinfold technique ${ }^{(34)}$.

\section{Self-reported measures of food intake}

Weighed dietary records. Subjects were instructed to carry out two $3 \mathrm{~d}$ weighed dietary records (WDR) over the $12 \mathrm{~d}$ period. These $3 \mathrm{~d}$ WDR occurred during the overt phases of the $12 \mathrm{~d}$. Each $3 \mathrm{~d}$ period was matched to $3 \mathrm{~d}$ of non-weighing (covert phase), with the order of the overt and covert phases randomised across the subjects. Each subject was asked to weigh, using portable scales (Soehnle model 820; Soehnle), and record in a food diary all food items eaten and all fluids drunk $^{(21)}$. Scales were calibrated before use by the subjects. Full written and verbal information on how to carry this out was given at the beginning of the study.

$24 \mathrm{~h}$ recalls. A trained member of staff carried out six $24 \mathrm{~h}$ recalls based on the multiple-pass design ${ }^{(35)}$. Each $24 \mathrm{~h}$ recall was conducted the day after a WDR was completed during the overt phase of the $12 \mathrm{~d}$, hence following the same randomisation as the $3 \mathrm{~d}$ WDR. Suitable portion sizes and weights were assigned to each food item ${ }^{(36)}$.

$7 d$ diet history. Subjects completed a $7 \mathrm{~d}$, multiple-pass, DH with a trained member of staff before the study ${ }^{(35)}$. Subjects were asked to describe what their usual food intake would be in a week, in household terms. Each DH was entered into a spreadsheet, and suitable portion sizes were assigned to each food item from the UK Food Standard Agency book on average portion sizes ${ }^{(36)}$.

FFQ. Subjects completed a 150-item, semi-quantitative FFQ on two occasions. The FFQ was developed as a general tool for dietary assessment, and relates to the frequency of consumption of specific foods over the preceding 2 to 3 months ${ }^{(22)}$. On day 1 , subjects were asked to complete the FFQ with reference to the previous 2 to 3 months (FFQ1), and the previous $14 \mathrm{~d}$ on day 15 (FFQ2). Mean daily energy and nutrient intakes were obtained.

\section{Food intake analysis}

Analyses were carried out for $24 \mathrm{~h}$ energy and nutrient intakes from the LWI, $3 \mathrm{~d}$ WDR, $24 \mathrm{~h}$ recall and the $7 \mathrm{~d} \mathrm{DH}$ using Diet 5 (Robert Gordon University, Aberdeen). Nutritional information from manufacturers was added to the Diet 5 database for processed foods. Dietary data were then exported from Diet 5 and a series of checks for outliers and erroneous values (such as $100 \mathrm{~g}$ of instant coffee instead of $1 \mathrm{~g}$ ) made.

\section{Recruitment and ethics}

Prospective volunteers were invited to visit the HNU. All procedures involved in the study and any discomfort or risk they may have posed were explained. The present study was conducted according to the guidelines laid down in the Declaration of Helsinki, and all procedures involving human subjects were approved by the Joint Ethical Committee of the Grampian Health Board and the University of Aberdeen. Written informed consent was obtained from all subjects.

\section{Statistical analyses}

All analyses were performed using the Genstat 5 release 4.1 statistical package (Genstat 5 Committee, Numerical Algorithms Group, 1997). Paired Student's $t$ tests were used for comparison of EI (LWI) with EE (DLW). A Bland-Altman plot was used to compare the deviations between the methods used for the assessment of EB. ANOVA was used to compare differences in food intake methods observed between men and women and between different BMI categories and also for average EI, EE, change in body weight over the $12 \mathrm{~d}$ period and EB (EI - EE).

Linear regressions, and segmented linear regressions, were carried out to examine the relationship between the average rate of weight change per $\mathrm{d}$ and energy difference (intake minus expenditure) for (1) all subjects, (2) male and females, (3) subjects with a BMI $\leq 25$ and $>25 \mathrm{~kg} / \mathrm{m}^{2}$.

\section{Results} Validation of the covert-weighed intakes with the
components of energy balance

Energy intake. Table 2 gives the average daily EI (LWI), expenditure and balance. The average daily EI calculated from the LWI was $11.3 \mathrm{MJ}$ for the fifty-nine subjects. Men consumed 17\% more energy than women. There was no significant difference between LWI EI or EE estimated from DLW ( $n 59, P=0.652$ ). The relationship between EI and EE was also plotted as a Bland-Altman diagram (Fig. 2). This plot shows the spread of the differences (EI - EE) against the mean of the two methods. There were four individuals outside the $\pm 2 \mathrm{SD}$ limits. These outliers were associated with individual changes in body weight over the DLW measurement period. Overall, it can be demonstrated that there is a good spread in the data with no apparent trend. As might be expected, there were significant differences in $\mathrm{EE}$ between men and women $(P<0 \cdot 001)$, with men expending $12 \cdot 14 \mathrm{MJ} / \mathrm{d}$ compared with $9 \cdot 91 \mathrm{MJ} / \mathrm{d}$ for women (SED $0 \cdot 483 \mathrm{MJ}$ / d). Body-weight change did not differ significantly from zero for the group as a whole $(P=0 \cdot 16)$ or for males $(P=0 \cdot 14)$ or females $(P=0 \cdot 19)$ separately. The relationship between EI - EE and $\mathrm{EB}$, estimated from the change in body weight, was examined. If the estimates of EI were biased, then the regression line would not go through zero EB at the zero rate of weight change per $d$. The intercepts of the regression lines differed significantly 
Table 2. Average energy intake, energy expenditure, energy balance and rate of weight change over the $12 \mathrm{~d}$ period for men and women with BMI $20-25$ or $>25 \mathrm{~kg} / \mathrm{m}^{2}$

\begin{tabular}{|c|c|c|c|c|c|c|c|}
\hline & $\begin{array}{c}\text { Female } \\
\left(\mathrm{BMI} 20-25 \mathrm{~kg} / \mathrm{m}^{2} \text { ) }\right.\end{array}$ & $\begin{array}{c}\text { Female } \\
\left(\text { BMl }>25 \mathrm{~kg} / \mathrm{m}^{2}\right)\end{array}$ & $\begin{array}{c}\text { Male } \\
\left(\text { BMI } 20-25 \mathrm{~kg} / \mathrm{m}^{2}\right)\end{array}$ & $\begin{array}{c}\text { Male } \\
\left(\text { BMI }>25 \mathrm{~kg} / \mathrm{m}^{2}\right)\end{array}$ & $\begin{array}{l}\text { Female } \\
\text { (all) }\end{array}$ & $\begin{array}{l}\text { Male } \\
\text { (all) }\end{array}$ & All \\
\hline $\begin{array}{l}\text { Average energy } \\
\text { intake }^{\star}(\mathrm{MJ} / \mathrm{d})\end{array}$ & 9.85 & $10 \cdot 55$ & 11.97 & $12 \cdot 48$ & $10 \cdot 17$ & $12 \cdot 30$ & $11 \cdot 25$ \\
\hline $\begin{array}{l}\text { Average energy } \\
\text { expenditure }(\mathrm{MJ} / \mathrm{d})\end{array}$ & 9.96 & $9 \cdot 85$ & $11 \cdot 78$ & $12 \cdot 36$ & 9.91 & $12 \cdot 14$ & 11.05 \\
\hline $\begin{array}{l}\text { Average energy } \\
\text { balance } \neq(\mathrm{MJ} / \mathrm{d})\end{array}$ & -0.10 & 0.70 & 0.20 & 0.13 & 0.26 & 0.15 & 0.21 \\
\hline $\begin{array}{l}\text { Average rate of weight } \\
\text { change }(\mathrm{kg} / \mathrm{d})\end{array}$ & -0.012 & -0.011 & 0.008 & -0.035 & -0.011 & -0.019 & -0.015 \\
\hline
\end{tabular}

* Measured using laboratory-weighed intakes.

$\uparrow$ Measured using doubly labelled water.

$\ddagger$ Energy intake minus energy expenditure.

from zero for (1) all subjects ( $-0.019 \mathrm{~kg} / \mathrm{d}, P=0.039)$ and (2) subjects with a BMI $>25 \mathrm{~kg} / \mathrm{m}^{2}(-0.038 \mathrm{~g} / \mathrm{d}, P=0 \cdot 023)$. However, when the regressions were analysed separately for subjects in positive and negative EB using segmented linear regression, the intercepts of the regression lines were not significantly different from zero for (1) all subjects, (2) male and females, and (3) subjects with a BMI $\leq 25$ and $>25 \mathrm{~kg} / \mathrm{m}^{2}$ (see the Supplementary Appendix, available online).

There was thus a good agreement between EB, estimated from the change in body weight, and EI - EE (as determined by the linear regression).

On analysis of the video surveillance, it was found that $64 \%$ of the food items consumed by a subject were seen by an investigator reviewing the tape. This accounted for $71 \%$ of energy consumed during the $12 \mathrm{~d}$ period.

\section{Effect of being observed on feeding behaviour, energy and macronutrient intake}

Table 3 compares the overt and covert phases of the LWI for men, women and all subjects together for absolute energy and macronutrient intakes as well as the percentage of EI derived from each of the macronutrients. Comparison of the overt and covert phases of the LWI demonstrated the effect of self-recording food intake on actual feeding behaviour. This we have termed the 'observation effect'. The overt phase (10.9 MJ/d) was significantly $(P<0 \cdot 01)$ lower than the covert phase $(11.6 \mathrm{MJ} / \mathrm{d})$ for all subjects. The average difference between the two phases was $5 \%$ overall ( $n$ 59), with females altering their feeding behaviour to a greater extent $(-8 \%)$ than males $(-3 \%)$. Women altered their protein $(-8 \% P<0.001)$, fat $(-12 \% P<0.01)$ and carbohydrate $(-6 \%, P<0.05)$ intakes to a greater extent than men, while men had a significantly lower alcohol intake during the overt phase compared with the covert phase $(P<0 \cdot 01)$. However, when the macronutrients were expressed as the percentage of EI, no significant differences between the phases were observed except for alcohol intake for men, which was slightly lower during the overt phase $(P<0 \cdot 05)$

The main effects of being observed, therefore, are that EI dropped on average by $5 \%$. This was mainly due to decreases in protein, carbohydrate and, especially, fat intakes in women. Men were less pronounced in this regard with the exception of their alcohol intake.
Difference between what people eat and what they record eating, having taken account of changes in eating behaviour when being observed

We have defined the 'reporting effect' as the discrepancy between what people actually eat and what they say they eat, having taken account of the observation effect. Table 4 compares absolute energy and macronutrients for the selfreported methods of quantifying food intake in comparison with the overt phase of the LWI, giving the percentage difference between the methods. This constitutes an estimate of the reporting effect. The results are given as a difference in energy and macronutrient intakes by the self-reported methods, relative to the 'gold standard'. This varied from $-5 \%$ for the WDR to $-15 \%$ for the FFQ2 in terms of absolute energy and macronutrients. Those dietary assessment methods that showed the largest percentage differences ( $\mathrm{DH}$ and $24 \mathrm{~h}$ recalls) for energy intake also had significant percentage differences for macronutrient intake. Differences in macronutrient intake between the overt phase of the LWI and the other dietary assessment methods were not significant when expressed as the percentage of energy. Indeed, there was no evidence of any strong macronutrient specificity in the reporting effect.

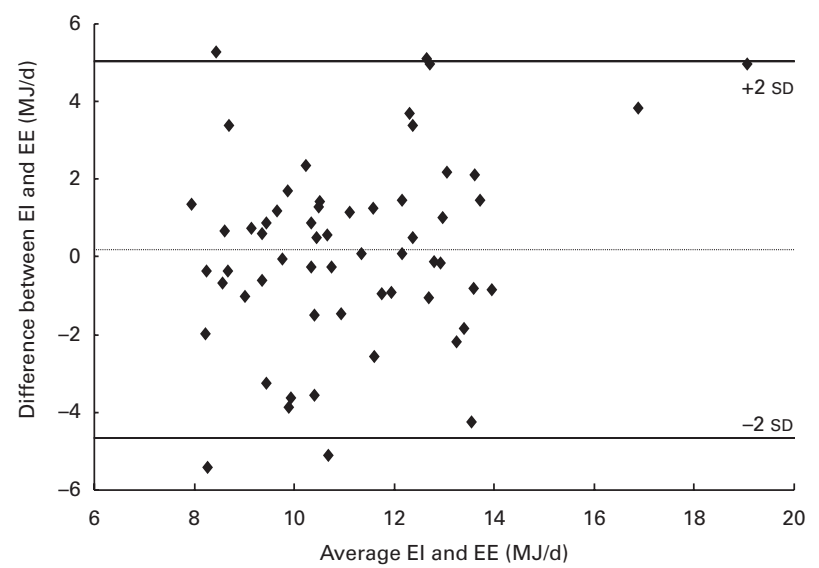

Fig. 2. Bland-Altman plot of difference in energy intake (EI) and energy expenditure (EE) (mean daily energy intake using the laboratory-weighed intake method minus mean daily energy expenditure using the doubly labelled water method) against the mean of the two measures for the fiftynine subjects who were included in the study. 
Table 3. Effect of monitoring food intake on feeding behaviour (observation effect)

(Mean values with their standard errors)*

\begin{tabular}{|c|c|c|c|c|c|c|c|}
\hline & \multicolumn{2}{|c|}{ LWI-C } & \multicolumn{2}{|c|}{ LWI-O } & \multicolumn{3}{|c|}{ Difference } \\
\hline & Mean & SE & Mean & SE & $\%$ & SE & $P$ \\
\hline \multicolumn{8}{|c|}{ Energy (MJ/d) } \\
\hline Females & $10 \cdot 6$ & 0.4 & $9 \cdot 7$ & 0.4 & $-8 \cdot 1$ & $2 \cdot 2$ & 0.001 \\
\hline Males & $12 \cdot 6$ & 0.6 & $12 \cdot 0$ & 0.5 & -2.5 & $2 \cdot 3$ & 0.277 \\
\hline All & 11.6 & 0.4 & $10 \cdot 9$ & 0.4 & $-5 \cdot 3$ & 1.6 & 0.002 \\
\hline \multicolumn{8}{|c|}{ Protein (MJ/d) } \\
\hline Females & 1.7 & 0.1 & 1.5 & $0 \cdot 1$ & -8.4 & $3 \cdot 2$ & 0.013 \\
\hline Males & 1.9 & $0 \cdot 1$ & 1.9 & 0.1 & 0.6 & $2 \cdot 6$ & 0.821 \\
\hline All & 1.8 & 0.1 & $1 \cdot 7$ & 0.1 & -3.8 & $2 \cdot 1$ & 0.077 \\
\hline \multicolumn{8}{|l|}{$\mathrm{CHO}(\mathrm{MJ} / \mathrm{d})$} \\
\hline Females & $5 \cdot 1$ & 0.2 & 4.8 & $0 \cdot 2$ & -5.5 & $2 \cdot 7$ & 0.049 \\
\hline Males & 5.9 & 0.2 & $5 \cdot 7$ & 0.2 & -1.5 & $2 \cdot 4$ & 0.538 \\
\hline All & $5 \cdot 5$ & 0.2 & $5 \cdot 2$ & 0.2 & -3.5 & 1.8 & 0.059 \\
\hline \multicolumn{8}{|l|}{ Fat $(\mathrm{MJ} / \mathrm{d})$} \\
\hline Females & 3.5 & 0.3 & $3 \cdot 1$ & 0.2 & $-12 \cdot 0$ & 4.0 & 0.005 \\
\hline Males & $4 \cdot 3$ & $0 \cdot 3$ & $4 \cdot 1$ & 0.3 & $-1 \cdot 0$ & $3 \cdot 7$ & 0.793 \\
\hline All & 3.9 & 0.2 & 3.6 & 0.2 & -6.4 & $2 \cdot 8$ & 0.025 \\
\hline \multicolumn{8}{|c|}{ Alcohol (MJ/d) } \\
\hline Females & 0.3 & 0.1 & 0.3 & $0 \cdot 1$ & $27 \cdot 0$ & $14 \cdot 8$ & 0.569 \\
\hline Males & 0.5 & 0.1 & 0.4 & $0 \cdot 1$ & $-14 \cdot 8$ & 8.9 & 0.014 \\
\hline All & 0.4 & 0.1 & 0.3 & 0.0 & $5 \cdot 7$ & 8.9 & 0.141 \\
\hline
\end{tabular}

LWI, laboratory-weighed intakes; $\mathrm{CHO}$, carbohydrates.

* Values are given as absolute energy intakes and absolute energy intakes from the macronutrients for the covert $(\mathrm{C})$ and overt $(\mathrm{O})$ phases of the study.

\section{Combined influence of the observation and reporting effects on energy and macronutrient intakes}

Table 5 compares the absolute energy and macronutrient intakes between each self-reported method of food intake reporting with the covert phase of the LWI. Table 6 gives the corresponding values for the percentage of EI from the macronutrients. The differences between the covert phase of the LWI and the self-reported methods equate to the sum of the observation and reporting effects that occurred during food intake measurements. This is the total misreporting effect'. The self-reported methods of quantifying food intake significantly under-estimated EI compared with the covert phase of the LWI $(-10$ and $-21 \%$ for the WDR and DH, respectively). The exception to this was FFQ1, where there was a $7 \%$ (NS) difference between the two methods. Percentage differences were similar for the $\mathrm{DH}$, recall and FFQ2 across men and women. There were also significant differences for most of the macronutrients, when expressed in absolute terms. When expressing macronutrients as a percentage of EI, significance levels were more variable for the differences between the 'gold standard' and the self-reported methods of assessing food intake.

\section{Discussion}

A major problem in cross-validation of dietary assessment techniques is that they are all self-reported and, by definition, subjective methods. Errors due to the reporting or observation effects would tend to co-vary giving the erroneous impression of cross-validation ${ }^{(6,20)}$. We therefore designed a Feeding Behaviour Suite and experimental protocol, which used EB methodology in combination with dietary assessment techniques, to concurrently measure actual intake and to validate that measurement. Once validated, the 'gold standard' could then be compared with common methods for assessing dietary intakes. The 'gold standard' measure of actual intake was validated using independent measures of the change in EB using the DLW technique and body-weight change ${ }^{(13,14)}$. There was good agreement between the independent assessments of the components of the EB equation (Table 2 and Fig. 2; see the Supplementary Appendix, available online), confirming the validity of the 'gold standard'. These conclusions are further confirmed by the regression of EI - EE with change in body weight (two independent assessments of EB), which allowed us to conclude that the 'gold standard' was accurately measuring EI. Second, the fact that subjects were, on average, in EB over the $12 \mathrm{~d}$ period of the study removes any doubt that the laboratory environment influenced feeding or activity behaviour differentially to the extent that EB would be perturbed.

\section{Identifying the nature and extent of the discrepancy between what people eat and what they eat when they are observed (observation effect)}

Each subject was provided with food that was typical of their normal diet (based on an initial $7 \mathrm{~d} \mathrm{DH}$ and shopping lists). Subjects' food was purchased on the basis of the $7 \mathrm{~d} \mathrm{DH}$ and shopping lists. This was independently assessed using a FFQ, which asked subjects about their intake in the 2 to 3 months before the study. These limited insights are the only evidence to suggest that the subjects were actually eating a diet similar to that which they normally ate. The study was not designed to monitor 'habitual' intake but to ensure that subjects consumed familiar foods from their normal everyday diet.

Comparison of the LWI during the covert phases with that during the overt phases gave an estimate of the effect of overtly recording food intake on eating behaviour (observation effect). The mean EI was 5\% lower in the overt phase compared with the covert phase in which subjects were not asked to record their food intake. This was primarily due to the $8 \%$ drop in EI in women. The 3\% drop in men was not significant. While women showed a marked drop in their fat intake of $12 \%$ when reporting their food intake, men dropped their alcohol intake by $15 \%$ compared with when they were not reporting their food intake. However, the absolute change in alcohol intake was relatively small, amounting to about 0.3 standard alcoholic drinks/d. Some subjects may be more sensitive about reporting foods high in these two nutrients ${ }^{(5,37)}$. These discrepancies are due to actual changes in behaviour as a consequence of subjects recording their own food intake or the effect of knowing their intake is being observed.

There was no evidence of a macronutrient-specific component to the reporting effect (i.e. the difference between actual intake during the overt phase and that measured using WDR, DH, recall or FFQ). When macronutrient intakes were expressed as their relative contribution to EI (percentage 
Table 4. Percentage differences between the overt phase of laboratory-weighed intakes and other self-reported methods (reporting effect) (Percentage difference values with their standard errors) ${ }^{*}$

\begin{tabular}{|c|c|c|c|c|c|c|c|c|c|c|c|c|c|c|c|}
\hline & \multicolumn{3}{|c|}{ WDR } & \multicolumn{3}{|c|}{$\mathrm{DH}$} & \multicolumn{3}{|c|}{ Recall } & \multicolumn{3}{|c|}{ FFQ1 } & \multicolumn{3}{|c|}{ FFQ2 } \\
\hline & $\%$ Difference & SE & $P$ & $\%$ Difference & SE & $P$ & $\%$ Difference & SE & $P$ & \% Difference & SE & $P$ & $\%$ Difference & SE & $P$ \\
\hline \multicolumn{16}{|c|}{ Energy (MJ/d) } \\
\hline Females & $-5 \cdot 3$ & $2 \cdot 0$ & 0.012 & $-13 \cdot 2$ & $3 \cdot 2$ & 0.000 & $-8 \cdot 7$ & $2 \cdot 3$ & 0.000 & 0.5 & $6 \cdot 8$ & 0.938 & $-9 \cdot 0$ & $4 \cdot 3$ & 0.048 \\
\hline Males & -4.8 & $2 \cdot 2$ & 0.035 & $-17 \cdot 8$ & 3.8 & 0.000 & -11.5 & $2 \cdot 1$ & 0.000 & $-2 \cdot 9$ & 5.8 & 0.617 & $-21 \cdot 3$ & $4 \cdot 1$ & 0.000 \\
\hline All & $-5 \cdot 1$ & 1.5 & 0.001 & $-15 \cdot 5$ & 2.5 & 0.000 & $-10 \cdot 1$ & 1.6 & 0.000 & $-1 \cdot 3$ & 4.4 & 0.782 & $-15 \cdot 2$ & $3 \cdot 0$ & 0.000 \\
\hline \multicolumn{16}{|l|}{ Protein $(g / d)$} \\
\hline Females & $-4 \cdot 2$ & $2 \cdot 0$ & 0.041 & -5.4 & 3.7 & 0.158 & $-7 \cdot 7$ & $2 \cdot 0$ & 0.000 & $11 \cdot 1$ & $7 \cdot 2$ & 0.145 & 1.9 & 5.4 & 0.726 \\
\hline Males & 0.8 & 5.4 & 0.877 & -13.5 & 4.0 & 0.002 & $-11 \cdot 6$ & $2 \cdot 5$ & 0.000 & $6 \cdot 8$ & $5 \cdot 9$ & 0.258 & $-10 \cdot 6$ & $5 \cdot 0$ & 0.046 \\
\hline All & $-1 \cdot 7$ & $2 \cdot 9$ & 0.526 & -9.5 & $2 \cdot 8$ & 0.001 & -9.7 & 1.6 & 0.000 & 8.9 & $4 \cdot 6$ & 0.062 & $-4 \cdot 4$ & $3 \cdot 7$ & 0.252 \\
\hline \multicolumn{16}{|l|}{$\mathrm{CHO}(\mathrm{g} / \mathrm{d})$} \\
\hline Females & $-5 \cdot 9$ & 1.6 & 0.001 & $-15 \cdot 6$ & $3 \cdot 7$ & 0.000 & $-10 \cdot 1$ & $2 \cdot 6$ & 0.000 & 0.4 & $6 \cdot 9$ & 0.959 & -10.9 & $4 \cdot 2$ & 0.017 \\
\hline Males & -5.0 & $2 \cdot 4$ & 0.046 & $-22 \cdot 9$ & 3.5 & 0.000 & $-13 \cdot 7$ & $2 \cdot 2$ & 0.000 & $-5 \cdot 9$ & $6 \cdot 1$ & 0.342 & $-24 \cdot 0$ & $4 \cdot 1$ & 0.000 \\
\hline All & -5.4 & 1.4 & 0.000 & $-19 \cdot 3$ & 2.5 & 0.000 & -11.9 & 1.7 & 0.000 & $-2 \cdot 9$ & $4 \cdot 6$ & 0.535 & $-17 \cdot 6$ & 3.0 & 0.000 \\
\hline \multicolumn{16}{|l|}{ Fat $(\mathrm{g} / \mathrm{d})$} \\
\hline Females & $-3 \cdot 8$ & $4 \cdot 2$ & 0.342 & -9.4 & $4 \cdot 1$ & 0.031 & -4.9 & $4 \cdot 1$ & $0 \cdot 177$ & 4.9 & $9 \cdot 4$ & 0.613 & -0.8 & $7 \cdot 9$ & 0.921 \\
\hline Males & $-6 \cdot 8$ & $2 \cdot 2$ & 0.005 & $-16 \cdot 7$ & $5 \cdot 9$ & 0.008 & -9.5 & $2 \cdot 8$ & 0.002 & -3.9 & $7 \cdot 3$ & 0.597 & $-24 \cdot 1$ & 4.5 & 0.000 \\
\hline All & $-5 \cdot 3$ & $2 \cdot 4$ & 0.025 & $-13 \cdot 1$ & 3.6 & 0.001 & $-7 \cdot 2$ & $2 \cdot 5$ & 0.003 & 0.3 & $5 \cdot 9$ & 0.955 & $-12 \cdot 7$ & $4 \cdot 7$ & 0.011 \\
\hline \multicolumn{16}{|l|}{ Alcohol (g/d) } \\
\hline Females & $-1 \cdot 9$ & $3 \cdot 1$ & 0.477 & $-3 \cdot 7$ & 9.4 & 0.676 & -3.0 & $3 \cdot 3$ & 0.330 & $-12 \cdot 4$ & 6.4 & 0.058 & $-27 \cdot 0$ & $7 \cdot 6$ & 0.001 \\
\hline Males & 0.6 & $2 \cdot 3$ & 0.673 & 114.5 & 61.4 & 0.073 & -1.8 & $3 \cdot 7$ & 0.556 & $101 \cdot 0$ & $53 \cdot 7$ & 0.071 & 71.8 & 51.3 & 0.175 \\
\hline All & -1.3 & 1.9 & 0.401 & $56 \cdot 4$ & $32 \cdot 3$ & 0.088 & -2.4 & 2.5 & 0.271 & $46 \cdot 2$ & $28 \cdot 7$ & 0.115 & $23 \cdot 3$ & $27 \cdot 0$ & 0.399 \\
\hline
\end{tabular}

WDR, weighed dietary record; DH, diet history (7 d); $\mathrm{CHO}$, carbohydrates.

* Results are presented for absolute energy and macronutrient intakes. 
Table 5. Percentage differences between the covert phase of laboratory-weighed intakes and other self-reported methods (overall misreporting) (Percentage difference values with their standard errors)*

\begin{tabular}{|c|c|c|c|c|c|c|c|c|c|c|c|c|c|c|c|}
\hline & \multicolumn{3}{|c|}{ WDR } & \multicolumn{3}{|c|}{$\mathrm{DH}$} & \multicolumn{3}{|c|}{ Recall } & \multicolumn{3}{|c|}{ FFQ1 } & \multicolumn{3}{|c|}{ FFQ2 } \\
\hline & \% Difference & SE & $P$ & $\%$ Difference & SE & $P$ & \% Difference & SE & $P$ & $\%$ Difference & $\mathrm{SE}$ & $P$ & \% Difference & SE & $P$ \\
\hline \multicolumn{16}{|l|}{ Energy } \\
\hline Females & -13.1 & 2.5 & 0.000 & $-20 \cdot 7$ & 3.0 & 0.000 & $-16 \cdot 3$ & $2 \cdot 6$ & 0.000 & -8.5 & 5.5 & 0.138 & $-16 \cdot 3$ & 3.9 & 0.000 \\
\hline Males & -7.5 & $2 \cdot 8$ & 0.013 & -20.4 & 3.9 & 0.000 & $-13 \cdot 8$ & 3.0 & 0.000 & $-6 \cdot 2$ & 5.6 & 0.275 & -24.5 & 3.6 & 0.000 \\
\hline All & $-10 \cdot 3$ & 1.9 & 0.000 & -20.5 & 2.5 & 0.000 & $-15 \cdot 0$ & $2 \cdot 0$ & 0.000 & -7.3 & 3.9 & 0.067 & -20.5 & $2 \cdot 7$ & 0.000 \\
\hline \multicolumn{16}{|l|}{ Protein } \\
\hline Females & $-12 \cdot 9$ & 3.0 & 0.000 & -14.2 & 4.2 & 0.002 & $-15 \cdot 8$ & 3.3 & 0.000 & 0.1 & $6 \cdot 0$ & 0.995 & -8.3 & 4.2 & 0.062 \\
\hline Males & 1.9 & 6.6 & 0.777 & -14.2 & 3.8 & 0.001 & -11.2 & 3.4 & 0.002 & $6 \cdot 6$ & $6 \cdot 0$ & 0.277 & $-10 \cdot 6$ & 5.1 & 0.048 \\
\hline All & -5.4 & 3.8 & 0.149 & $-14 \cdot 2$ & $2 \cdot 8$ & 0.000 & -13.5 & $2 \cdot 3$ & 0.000 & $3 \cdot 4$ & 4.2 & 0.423 & -9.5 & 3.3 & 0.006 \\
\hline \multicolumn{16}{|l|}{$\mathrm{CHO}$} \\
\hline Females & -11.6 & $2 \cdot 2$ & 0.000 & $-21 \cdot 3$ & 3.4 & 0.000 & $-15 \cdot 6$ & $2 \cdot 8$ & 0.000 & $-6 \cdot 8$ & 5.6 & 0.251 & $-16 \cdot 6$ & 3.6 & 0.000 \\
\hline Males & -6.8 & $2 \cdot 8$ & 0.020 & -24.5 & 3.6 & 0.000 & $-15 \cdot 6$ & 2.5 & 0.000 & $-8 \cdot 1$ & 5.8 & 0.173 & $-26 \cdot 1$ & 3.5 & 0.000 \\
\hline All & -9.2 & 1.8 & 0.000 & -22.9 & 2.5 & 0.000 & $-15 \cdot 6$ & 1.8 & 0.000 & -7.5 & 4.0 & 0.071 & -21.4 & 2.5 & 0.000 \\
\hline \multicolumn{16}{|l|}{ Fat } \\
\hline Females & -14.9 & 5.7 & 0.014 & $-21 \cdot 6$ & 4.4 & 0.000 & $-17 \cdot 4$ & 4.5 & 0.000 & $-10 \cdot 8$ & $6 \cdot 8$ & 0.129 & -15.4 & $6 \cdot 2$ & 0.022 \\
\hline Males & -8.4 & 3.7 & 0.030 & $-18 \cdot 7$ & 6.5 & 0.007 & -10.4 & 4.6 & 0.030 & $-7 \cdot 2$ & 6.9 & 0.307 & -27.4 & $4 \cdot 3$ & 0.000 \\
\hline All & -11.6 & 3.4 & 0.001 & $-20 \cdot 1$ & 3.9 & 0.000 & $-13 \cdot 8$ & $3 \cdot 2$ & 0.000 & -8.9 & 4.8 & 0.071 & -21.5 & 3.8 & 0.000 \\
\hline \multicolumn{16}{|l|}{ Alcohol } \\
\hline Females & 21.2 & 13.7 & 0.139 & 6.5 & 12.8 & 0.630 & 23.5 & $15 \cdot 5$ & 0.145 & $9 \cdot 4$ & $13 \cdot 1$ & 0.493 & -5.0 & $16 \cdot 7$ & 0.796 \\
\hline Males & -12.9 & $8 \cdot 1$ & 0.111 & $68 \cdot 3$ & 49.2 & 0.179 & -15.5 & 8.2 & 0.061 & 54.2 & $41 \cdot 1$ & 0.201 & 31.0 & $38 \cdot 7$ & 0.503 \\
\hline All & 3.9 & 8.2 & 0.672 & 37.9 & 25.9 & 0.153 & 3.7 & 9.0 & 0.718 & 32.6 & $22 \cdot 2$ & 0.152 & 14.8 & $21 \cdot 8$ & 0.588 \\
\hline
\end{tabular}

WDR, weighed dietary record; DH, diet history (7d); $\mathrm{CHO}$, carbohydrates.

* Differences are given as absolute values. 


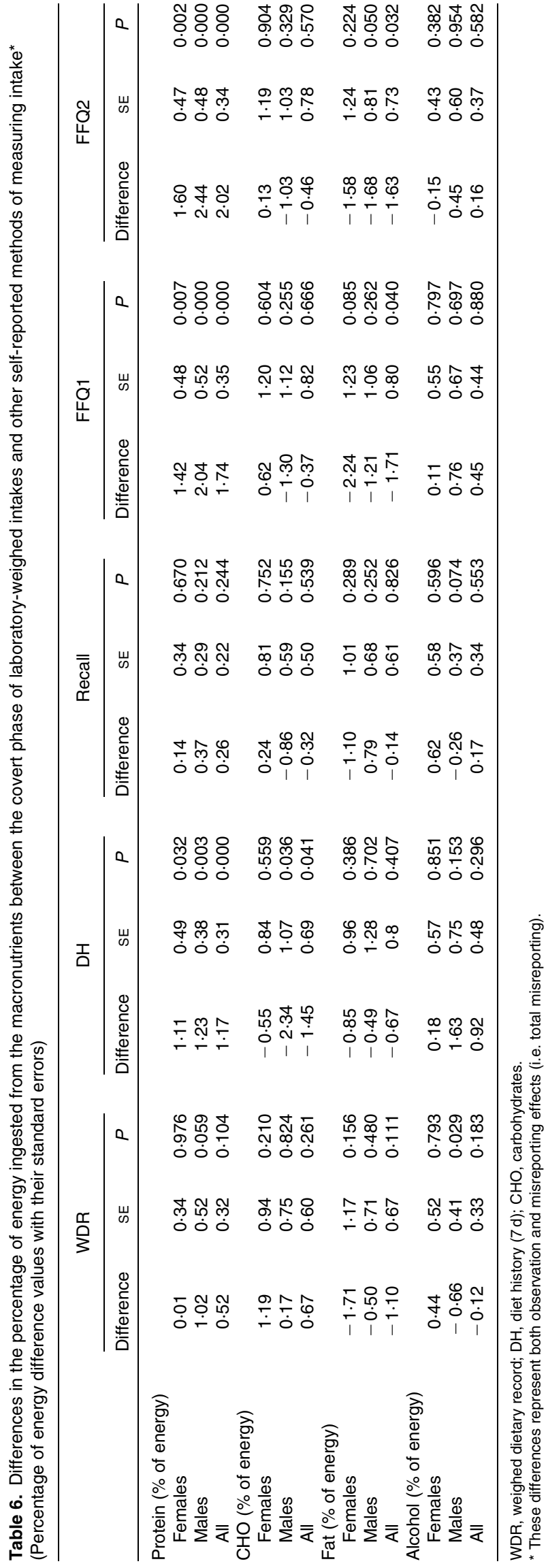

of energy), the differences between WDR, DH, recall, FFQ2 and the reference LWI (Table 6) appeared smaller than when differences in absolute values (g) were compared (Table 5) and fewer significant differences were found between the methods, at least for the main macronutrients. This effect has been noted previously by Kipnis et al. ${ }^{(38)}$ and is a consequence of the inevitable correlation between errors, or low energy reporting, in macronutrients and energy as the total EI is the sum of the energy from the individual macronutrients. There was little macronutrient-specific effect of observation, and therefore energy-adjusted macronutrient intakes were less affected than were absolute intakes. The use of energy-adjusted nutrient intakes has been suggested as a way of improving (albeit slightly) the performance of some dietary assessment tools when considering the associations between diet and health ${ }^{(38)}$.

The present study raises the possibility that differences in macronutrient intake between low-energy reporters and non-low-energy reporters, found in diet surveys ${ }^{(6,9,39)}$, may be due more to changes in feeding behaviour when being observed (observation effect) than differences between what people actually eat and what they report eating (reporting effect). This is a concern because current diet survey methods are unable to detect changes in subjects' feeding behaviour relative to when they are not being monitored. When recording food intake, changes in diet can be assessed at the level of the individual using similar techniques to those used in the present study ${ }^{(23-25,40)}$. However, under-eating relative to energy requirements may not be exactly the same as a change in behaviour under observation. Assessment of under-recording of EI using water balance makes the same assumptions as that of other biomarkers. As noted by Goris \& Westerterp ${ }^{(23)}$, 'A good recording of water intake does not necessarily imply that the same holds for the recording of food intake'. Nevertheless, Goris et al. showed the impact of weighing subjects at the beginning and end of a $7 \mathrm{~d}$ dietary measurement period on body weight in well-motivated lean women $^{(23)}$ and in obese men ${ }^{(24)}$. When adult males (mean BMI $24 \mathrm{~kg} / \mathrm{m}^{2}$, range $19-36 \mathrm{~kg} / \mathrm{m}^{2}$ ) completed two $7 \mathrm{~d}$ weighed food records, negative changes in body weight suggested an observation effect of about $10 \%$ of energy requirements, and changes in body weight were not related to $\mathrm{BMI}^{(41)}$. Insights into the likely size of the observation effect can also be gleaned from dietary intake measures over the course of $7 \mathrm{~d}$ provided body weight is recorded at the beginning and end of this period. In a $14 \mathrm{~d}$ dietary intervention study, subjects completed weighed food intake diaries during the second week. Body weight was recorded on days 1,8 and 15, allowing changes in $\mathrm{EB}$ due to the observation effect alone to be assessed. It was clear that the subjects altered their intake during the recording week relative to the week before, and this effect was in the order of $3 \mathrm{MJ} / \mathrm{d}^{(42)}$. Simply measuring weight in this way can give an estimate of how EI may vary in relation to EB during the period of measurement. The implication for diet surveys is that to link self-reported intake to cheap, objective indices of EB; records of approximately $7 \mathrm{~d}$ should be used in well-structured populations. In addition, weight should be recorded immediately 
before and after the measurement period. This will allow some estimate of the observation effect to be assessed with reference to $\mathrm{EB}$.

The reporting effect was identical in men and women and amounted to $5 \%$ of EI for the WDR. Both the observation and reporting effects were greatest for the $\mathrm{DH}$ and FFQ2 compared with the other methods, although FFQ2 covered all four $3 \mathrm{~d}$ covert and overt phases combined and was not directly comparable to the other methods. Furthermore, FFQ are not usually used to measure EI but rather to rank nutrient intake adjusted for EI. For the WDR at least, the reporting effect was as high as the observation effect and both combined to produce an average misreporting effect of approximately $10 \%$ under laboratory conditions.

The present study is unique in that it has established two separate but simultaneous features associated with misreporting; the observation effect and the reporting effect. Scatter plots of the observation and reporting effects and their combined difference to the LWI (shown in the Supplementary Appendix, available online) demonstrated that, in these fiftynine subjects at least, both effects were continuously distributed and occurred in most subjects to some degree ${ }^{(43)}$. Furthermore, current diet survey methods are unable to precisely or accurately measure either discrepancy, particularly for subjects with a higher EI:BMR ratio. Body weight can only identify observation effects that significantly alter $\mathrm{EB}$, i.e. under-eating relative to energy requirements. A change in the composition of the diet with a similar EI would go undetected.

Evidence from the present study suggests that the observation effect is more pronounced in women than in men, and is more specific for fat intake in women. For men, alcohol intake changed the most. However, this was a relatively small study and the applicability of these findings needs to be assessed in future studies, as this is the first study to quantify these effects. The reporting effect ranged from $-5 \%$ for the WDR to $-21 \%$ for the DH and FFQ2. The reporting effect appears to be the most detectable component of misreporting. It is of concern that the most specific discrepancy with reference to nutrient intake is currently undetectable (observation effect). The results of this problem await the development of precise, accurate biomarkers of nutrient balance status. While this is theoretically possible in terms of 'free-living indirect calorimetry', we are still a long way off achieving a practical solution.

\section{Supplementary material}

To view supplementary material for this article, please visit http://dx.doi.org/10.1017/S0007114514000154

\section{Acknowledgements}

The present study was funded by the Food Standards Agency, UK. The Food Standards Agency had no role in the design, analysis or writing of this article.

The authors' responsibilities were as follows: R. J. S., L. M. O'R. and G. W. H. designed the research; L. M. O'R. and Z. F. conducted the research and analysed the data; G. W. H. performed the statistical analyses; P. R. carried out the DLW analysis; R. J. S. had primary responsibility for the final content; R. J. S., L. M. O'R., Z. F., S. W. and M. B. E. L. wrote the paper.

None of the authors had a potential conflict of interest.

\section{References}

1. Kant AK \& Graubard BI (2005) Energy density of diets reported by American adults: association with food group intake, nutrient intake, and body weight. Int J Obes (Lond) 29, 950-956.

2. Corwin RL, Hartman TJ, Maczuga SA, et al. (2006) Dietary saturated fat intake is inversely associated with bone density in humans: analysis of NHANES III. J Nutr 136, 159-165.

3. Liangpunsakul S (2010) Relationship between alcohol intake and dietary pattern: findings from NHANES III. World $J$ Gastroenterol 16, 4055-4060.

4. Romaguera D, Guevara M, Norat T, et al. (2011) Mediterranean diet and type 2 diabetes risk in the European Prospective Investigation into Cancer and Nutrition (EPIC) study: the InterAct project. Diabetes Care 34, 1913-1918.

5. Macdiarmid J \& Blundell J (1998) Assessing dietary intake: who, what and why of under-reporting. Nutr Res Rev 11, $231-253$.

6. Livingstone MBE \& Black AE (2003) Markers of the validity of reported energy intake. J Nutr 133, 895S-920S.

7. Singh R, Martin BR, Hickey Y, et al. (2009) Comparison of self-reported, measured, metabolizable energy intake with total energy expenditure in overweight teens. Am J Clin Nutr 89, 1744-1750.

8. Forrestal SG (2011) Energy intake misreporting among children and adolescents: a literature review. Matern Child Nutr 7, 112-127.

9. Rennie KL, Coward A \& Jebb SA (2007) Estimating underreporting of energy intake in dietary surveys using an individualised method. Br J Nutr 97, 1169-1176.

10. Tooze JA, Krebs-Smith SM, Troiano RP, et al. (2012) The accuracy of the Goldberg method for classifying misreporters of energy intake on a food frequency questionnaire and 24-h recalls: comparison with doubly labeled water. Eur J Clin Nutr 66, 569-576.

11. Prentice AM, Black AE, Coward WA, et al. (1986) High levels of energy expenditure in obese women. $\mathrm{Br}$ Med $J \mathbf{2 9 2}$, 983-987.

12. Bandini LG, Schoeller DA, Cyr HN, et al. (1990) Validity of reported energy intake in obese and nonobese adolescents. Am J Clin Nutr 52, 421-425.

13. Schoeller DA (1990) How accurate is self-reported dietary energy intake. Nutr Rev 48, 373-379.

14. Black AE, Prentice AM, Goldberg GR, et al. (1993) Measurements of total energy expenditure provide insights into the validity of dietary measurements of energy intake. $J \mathrm{Am}$ Diet Assoc 93, 572-579.

15. Schoeller DA (2002) Validation of habitual energy intake. Public Health Nutr 5, 883-888.

16. Black AE \& Cole TJ (2000) Within- and between-subject variation in energy expenditure measured by the doublylabelled water technique: implications for validating reported dietary energy intake. Eur J Clin Nutr 54, 386-394.

17. Poppitt SD, Swann D, Black AE, et al. (1998) Assessment of selective under-reporting of food intake by both obese and non-obese women in a metabolic facility. Int $J$ Obes $\mathbf{2 2}$, 303-311.

18. Black AE, Goldberg GR, Jebb SA, et al. (1991) Critical evaluation of energy-intake data using fundamental principles of 
energy physiology. 2. Evaluating the results of published surveys. Eur J Clin Nutr 45, 583-599.

19. Black AE (2000) The sensitivity and specificity of the Goldberg cut-off for EI: BMR for identifying diet reports of poor validity. Eur J Clin Nutr 54, 395-404.

20. Block $\mathrm{G}$ (1982) A review of validations of dietary assessment methods. Am J Epidemiol 115, 492-505.

21. Bingham SA (1987) The dietary assessment of individuals; methods, accuracy, new techniques and recommendations. Nutr Abstr Rev 57, 705-742.

22. Masson LF, McNeill G, Tomany JO, et al. (2003) Statistical approaches for assessing the relative validity of a foodfrequency questionnaire: use of correlation coefficients and the kappa statistic. Public Health Nutr 6, 313-321.

23. Goris AHC \& Westerterp KR (1999) Underreporting of habitual food intake is explained by undereating in highly motivated lean women. J Nutr 129, 878-882.

24. Goris AHC, Westerterp-Plantenga MS \& Westerterp KR (2000) Undereating and underrecording of habitual food intake in obese men: selective underreporting of fat intake. Am J Clin Nutr 71, 130-134.

25. Goris AHC, Meijer EP \& Westerterp KR (2001) Repeated measurement of habitual food intake increases underreporting and induces selective under-reporting. Br J Nutr 85, 629-634.

26. Bingham SA \& Cummings JH (1983) The use of 4-amino benzoic acid as a marker to validate the completeness of 24h urine collections in man. Clin Sci 64, 629-635.

27. Bingham SA \& Cummings JH (1985) Urine nitrogen as an independent validatory measure of dietary intake: a study of nitrogen balance in individuals consuming their normal diet. Am J Clin Nutr 42, 1276-1289.

28. Bingham SA, Murphy J, Waller E, et al. (1992) para-Amino benzoic acid in the assessment of completeness of 24-hour urine collections from hospital outpatients and the effect of impaired renal function. Eur J Clin Nutr 46, 131-135.

29. Holland B, Welch AA, Unwin ID, et al. (1991) The Composition of Foods, 5th ed. Cambridge: The Royal Society of Chemistry and Ministry of Agriculture, Fisheries and Food.

30. Coward WA \& Cole TJ (1991) The doubly labelled water method for the measurement of energy expenditure in humans: risks and benefits. In New Techniques in Nutritional Research, pp. 139-176 [RG Whitehead and A Prentice, editors]. London: Academic Press.
31. Coward WA (1989) Calculation of pool sizes and flux rates In The Doubly Labelled Water Method for Measuring Energy Expenditure: Technical Recommendations for Use in Humans. A Consensus Report by the IDECG Working Group, pp. 48-68 [AM Prentice, editor]. Vienna: International Atomic Energy Agency.

32. Black AE, Prentice AM \& Coward WA (1986) Use of food quotients to predict respiratory quotients for the doubly labelled water method of measuring energy expenditure. Hum Nutr Clin Nutr 40, 381-391.

33. Elia M \& Livesey G (1992) Energy expenditure and fuel selection in biological systems: the theory and practice of calculations based on indirect calorimetry and tracer methods. World Rev Nutr Diet 70, 68-131.

34. Durnin JVGA \& Womersley J (1974) Body fat assessed from total body density and its estimation from skinfold thickness: measurements on 481 men and women aged from 16 to 72 years. Br J Nutr 32, 77-97.

35. Jonnalagadda SS, Mitchell DC, Smiciklas-Wright $\mathrm{H}$, et al. (2000) Accuracy of energy intake data estimated by a multiple-pass, 24-hour dietary recall technique. J Am Diet Assoc 100, 303-308.

36. Food Standards Agency (1994) Food Portion Sizes, 2nd revised ed. London: MAFF.

37. Rennie KL, Siervo M \& Jebb SA (2006) Can self-reported dieting and dietary restraint identify underreporters of energy intake in dietary surveys? J Am Diet Assoc 106, 1667-1672.

38. Kipnis V, Subar AF, Midthune D, et al. (2003) Structure of dietary measurement error: results of the OPEN biomarker study. Am J Epidemiol 158, 14-21.

39. Poslusna K, Ruprich J, de Vries JH, et al. (2009) Misreporting of energy and micronutrient intake estimated by food records and 24 hour recalls, control and adjustment methods in practice. Br J Nutr 101, Suppl. 2, S73-S85.

40. Goris AHC \& Westerterp KR (2000) Improved reporting of habitual food intake after confrontation with earlier results on food reporting. Br J Nutr 83, 363-369.

41. Milne AC, McNeill G \& Zakary A (1991) Weight change as an indicator of energy imbalance during 7 day weighed food intake studies. Ecol Food Nutr 26, 281-289.

42. Whybrow S, Mayer C, Kirk TR, et al. (2007) Effects of twoweeks' mandatory snack consumption on energy intake and energy balance. Obesity (Silver Spring) 15, 673-685.

43. O'Reilly L (2001) Mis-reporting of food intake by UK adults. PhD Thesis, University of Ulster at Coleraine. 